\title{
Research on air bearing eccentric cross gap of neutron stress spectrometer sample table support system
}

\author{
LI Yang*, WU Yunxin** \\ *Central South University, Changsha 410083, China, E-mail: liyangcsu12@163.com \\ **Central South University, Changsha 410083, China, E-mail: wuyunxincsu@163.com \\ cross'ref http://dx.doi.org/10.5755/j01.mech.23.2.14019
}

\section{Introduction}

Neutron diffraction is the only direct test method for measuring the stress field in the deep place of the component. This method has many advantages. First, for aluminum alloy material, the detection depth can reach decimeter levels. Second, as a non-destructive measurement, this method could monitor the change of internal stress of the component under the premise of not destroying the structure. Third, neutron diffraction could measure tinternal stress field and corresponding force of the large-shaped component. Therefore, high performance neutron stress testing instrument is of great significance to the modern engineering manufacture. The sample table is one of the key parts of the neutron stress spectrometer. The sample table is required to meet multi-dimensional movement of the large component and adjust the position accurately. The supporting system of sample table is the main bearing system. A prominent problem in the measurement of stress field is the vibration and friction between the sample table and the ground surface. Hence, air bearing technology could effectively eliminate friction and reduce vibration. The key supporting element of the sample table of the neutron stress spectrometer is the air bearing. Poor bearing capacity of common air static pressure bearing and cross-gap performance will limit the application of air bearing in large load bearing, high precision, and so on. Therefore, improving the rigidity of air bearing and its cross-gap performance could achieve stable motion and high precision measurement of the neutron stress spectrometer.

Chen and Lin [1] adopted resistance network equivalent and other effective methods to analyze the dynamic and static characteristics of rectangular air bearing with $\mathrm{X}$ groove, which indicated large bearing capacity and rigidity of air bearing. Renn and Hsiao [2] used computational fluid dynamics method to study the relationship between flow rate and the geometry of the orifice. Luong et al. [3] adopted numerical calculations to analyze the bearing capacity of porous air andconducted related experiments. Belforte et al. [4] designed experiments to analyze the air bearing of the center of the annular air hole and the pressure distribution of chamber to derive the calculation formula of the inlet flow rate and throttling coefficient of the air. Li and Ding [5] analyze the influence of the structural parameters of the central hole air bearing on bearing capacity as well as air flow and air maximum flow velocity. Further, when the intake hole became smaller, the impact of the length of the inlet hole on the bearing performance should not be ignored. Stout and Barrans [6] discussed the design of the precision machine, influence of air pressure, and film thickness on the bearing performance. Belforte et al. [7, 8] used simulation and experiment to study the pressure distribution, air flow rate, and stiffness of air hydro-static bearing. The result indicated that pressure groove could improve bearing capacity significantly. Eleshaky [9] studied the radial pressure distribution of the center hole air hydro-static bearing. Miyatake and Yoshimoto [10] applied computer fluid dynamics and FE method to analyze the performance of the $0.05 \mathrm{~mm}$ air bearing and compared the results with the typical hydrostatic bearing. Hou et al. [11] and Huang et al. [12] studied the influence of structural parameters of air bearing on the bearing capacity and the film stiffness of the bearing capacity, air film thickness and the size of the air. Long et al. $[13,14]$ studied the relationship between the throttle type and the bearing capacity of the hydrostatic bearing of the annular air supply, and analyzed the anti-overturning and dynamic characteristics corresponding to the type of bearing. Zhang [15] came up with the structure of the uniform pressure groove with variable cross section and finally proved the correctness of the new bearing design. Li et al. [16] set up a new type of pressure groove based on the throttle air bearing by using FEM to analyze the bearing capacity of the new bearing and compared the results with the small hole type air bearing. Liu [17] studied the static performance of this kind of bearing under different working conditions. The empirical formula of the calculation of the stiffness of the bearing has been designed.

Although many scholars have conducted research on the static performance of the air static pressure bearing, the bearing capacity of the air bearing is generally low. The field of high bearing capacity and research on air bearing of neutron stress spectrometer is less. The static performance of large bearing and high precision air bearing static pressure bearing is not mature, and much work has to be studied. In addition, research on the air static pressure bearing of the eccentric cross-gap performance is less, and thus, the research of the performance of eccentric cross gap has important engineering application value.

\section{Air bearing combination scheme}

As can be seen in Fig. 1, sample table could translate in the $\mathrm{X} / \mathrm{Y} / \mathrm{Z}$ directions and rotate around the $\mathrm{Z}$ direction. Sample table is composed of translational mechanism, vertical lifting mechanism, rotation mechanism, and air bearing system.

Air bearing is the key part of the air bearing system, choose the correct structure of air bearing system must consider the bearing capacity, cross-gap performance, eccentric bearing performance, installing difficulty, and 
manufacturing difficulty. Air bearing system is shown in Fig. 2.

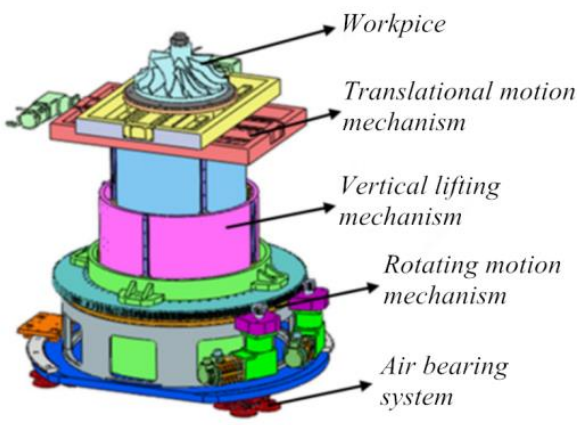

Fig. 1 Structures of sample table

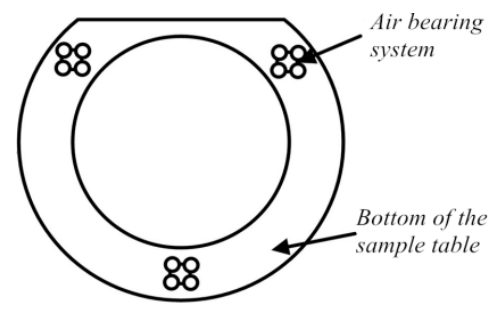

a

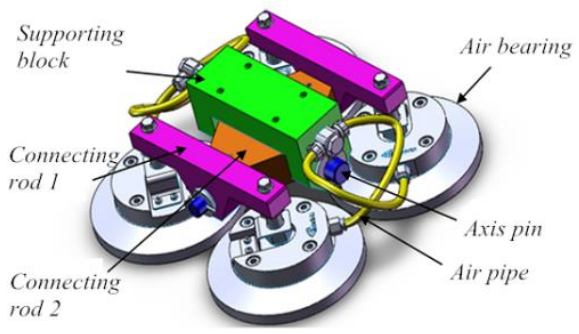

$\mathrm{b}$

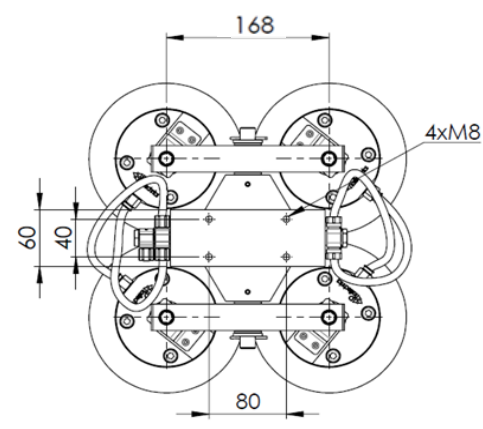

c

Fig. 2 Air bearing support system: a - schematic drawing of installation of air bearing system; b - structure diagram Dimensioned drawing

Installation distribution of air bearing in the equipment is shown in Fig. 2, a. Three combinations, which are composed of four bearings, are distributed at the bottom of the sample table. Four bearings are in each group and the two air bearings are connected together by a hinge structure. Each pair of bearings is connected through a hinge structure, such that one group consists of three hinged structures. The adjustment performance of the scheme is the best, through a number of hinge structures ensures that the combination of the bearing capacity is more stable and vertical to the bottom surface of the sample table. When a single bearing is placed in the gap, its performance change has little influence on overall capacity. The three groups of air flotation supporting system then become easy to adjust. Each bearing distribution is seen in Figs. 2, b and 2, c.

\section{Air bearing eccentric cross gap model and simulation}

\subsection{Reynolds equation for air bearing}

The performance parameters and the pressure distribution of the bearing air film region have a direct relationship with air pressure bearing [18-20]. The flow of air in the air pressure bearing is very complex, and the instantaneous velocity of air flow is very difficult to achieve. However, this concept is still applicable to the basic control equation of air lubrication theory. The Reynolds equation, which is based on average velocity field, is derived by calculating the average value of the air flow velocity in a certain period of time. To derive the Reynolds equation of air bearing, the assumption of the air lubricating medium is made.

First, the air pressure in the air gap is not changed, that is, the velocity of the $\mathrm{Z}$ direction is zero. Second, no relative motion was indicated between the upper surface of the air and the bearing boundary. Third, volume force and inertia force are neglected. Fourth, air flow state is laminar with air assumed as Newtonian fluid.

According to the assumption, the equation of continuous air could be expressed in the Cartesian coordinate system [18]:

$$
\frac{\partial \rho}{\partial t}+u \frac{\partial(\rho u)}{\partial x}+v \frac{\partial(\rho v)}{\partial y}+w \frac{\partial(\rho w)}{\partial z}=0,
$$

where $u, v$, and $w$ are the air velocity along the $x$-, $y$-, and $z$-axes respectively, and $\rho$ is air density. The motion equation of the air is the application of momentum conservation law in air dynamics and the Navier-Stokes (N-S) kinematic equations for compressible viscous flows are as follows [18]:

$$
\begin{aligned}
& \rho \frac{d u}{d t}=\rho f_{x}+\frac{\partial}{\partial x}\left\{\mu\left[2 \frac{\partial u}{\partial x}-\frac{2}{3}\left(\frac{\partial u}{\partial x}+\frac{\partial v}{\partial y}+\frac{\partial w}{\partial z}\right)\right]\right\}- \\
& -\frac{\partial \rho}{\partial x}+\frac{\partial}{\partial y}\left[\mu\left(\frac{\partial u}{\partial y}+\frac{\partial v}{\partial x}\right)\right]+\frac{\partial}{\partial z}\left[\mu\left(\frac{\partial w}{\partial x}+\frac{\partial u}{\partial z}\right)\right] ; \\
& \rho \frac{d v}{d t}=\rho f_{y}+\frac{\partial}{\partial y}\left\{\mu\left[2 \frac{\partial v}{\partial y}-\frac{2}{3}\left(\frac{\partial u}{\partial x}+\frac{\partial v}{\partial y}+\frac{\partial w}{\partial z}\right)\right]\right\}- \\
& -\frac{\partial \rho}{\partial y}+\frac{\partial}{\partial z}\left[\mu\left(\frac{\partial v}{\partial z}+\frac{\partial w}{\partial y}\right)\right]+\frac{\partial}{\partial x}\left[\mu\left(\frac{\partial u}{\partial y}+\frac{\partial v}{\partial x}\right)\right] ; \\
& \rho \frac{d w}{d t}=\rho f_{z}+\frac{\partial}{\partial z}\left\{\mu\left[2 \frac{\partial w}{\partial z}-\frac{2}{3}\left(\frac{\partial u}{\partial x}+\frac{\partial v}{\partial y}+\frac{\partial w}{\partial z}\right)\right]\right\}- \\
& -\frac{\partial \rho}{\partial z}+\frac{\partial}{\partial x}\left[\mu\left(\frac{\partial w}{\partial x}+\frac{\partial u}{\partial z}\right)\right]+\frac{\partial}{\partial y}\left[\mu\left(\frac{\partial v}{\partial z}+\frac{\partial w}{\partial y}\right)\right] .
\end{aligned}
$$

In Eqs. (2) to (4), $f_{x}, f_{y}$, and $f_{z}$ are the physical elements in the microorganism, and $\mu$ is air dynamic viscosity. According to the assumption, the N-S equation 
could be simplified as:

$$
\frac{\partial p}{\partial x}=\mu \frac{\partial^{2} u}{\partial z^{2}} ; \frac{\partial p}{\partial y}=\mu \frac{\partial^{2} v}{\partial z^{2}} ; \frac{\partial p}{\partial z}=0,
$$

where $p$ is pressure. Integrating $\mathrm{Z}$ in Eqs. (2) to (5) results in the following equation:

$$
u=\frac{1}{2 \mu} \frac{\partial p}{\partial x} z^{2}+c_{1} z+c_{2} ; \quad v=\frac{1}{2 \mu} \frac{\partial p}{\partial x} z^{2}+c_{3} z+c_{4}
$$

By the assumption that the surface of the air film is not related to the solid boundary, the film height is $h$. Hence, under the surface of air film, $z=0, u=0$ and $v=0$; on the surface of air film, $z=h, u=u_{1}$ and $v=v_{1}$, where $u_{1}$ and $v_{1}$ are constants. Bringing boundary conditions into Eq. (6), and eliminating integral constants $C_{1}, C_{2}, C_{3}, C_{4}$, will result in:

$$
\left.\begin{array}{l}
u=\frac{1}{2 \mu} \frac{\partial p}{\partial x} z(h-z)-\frac{u_{1}}{h} z+u_{1} \\
v=\frac{1}{2 \mu} \frac{\partial p}{\partial y} z(h-z)-\frac{v_{1}}{h} z+v_{1} .
\end{array}\right\}
$$

Integrate the continuity Eq. (1) over $Z$, the integral limit from 0 to $\mathrm{h}$ is as follows:

$$
\frac{\partial(\rho h)}{\partial t}+\int_{0}^{h}\left[\frac{\partial(\rho u)}{\partial x}+\frac{\partial(\rho v)}{\partial y}\right] d z=0 .
$$

Taking Eq. (7) into Eq. (8) and ignoring the small amount and the general expression of the Reynolds equation [18] will be:

$$
\begin{aligned}
& \frac{\partial}{\partial x}\left(\frac{\rho h^{3}}{\mu} \frac{\partial p}{\partial x}\right)+\frac{\partial}{\partial y}\left(\frac{\rho h^{3}}{\mu} \frac{\partial p}{\partial y}\right)= \\
& =12 \frac{\partial(\rho h)}{\partial t}+6 u_{1} \frac{\partial(\rho h)}{\partial x}+6 v_{1} \frac{\partial(\rho h)}{\partial y} .
\end{aligned}
$$

\subsection{Models for air bearing eccentric cross gap}

Because the neutron stress spectrometer is required to test different materials and components, thus, the sample table is required to be able to work anywhere in the test space, including the gap of marble floor. To study the influence of the gap on flow characteristics of air static pressure bearing, the corresponding simulation models were established for the different positions and gap parameters.

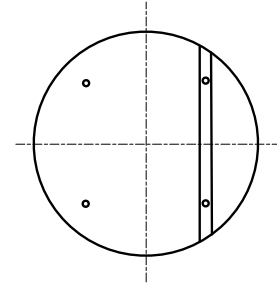

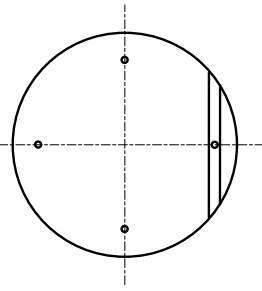

b
Fig. 3 Schematic models of air bearing eccentric cross gap: a - with two holes; $b$ - with one hole
The model was based on the actual situation of the air bearing cross gap. Although circumstances of cross gap are many, but in this paper, two typical models of eccentric cross gap with two holes and one hole were chosen to study. The modeling diagram is shown in Fig. 3. The effects of the gap on the static performance of the air static pressure bearing are mainly reflected on bearing capacity, air consumption, and overturning moment. The effects of different air supply pressure, gap width, gap depth, and gap height difference on static performance of the bearing are studied according to the two typical models.

The gap width and gap depth of the simulation model are set to $0.5 \mathrm{~mm}$, and other parameters are shown in Table 1. The FE models of air bearing eccentric cross gap with two holes and one hole are established for comparative analysis.

Table 1

Basic parameters of the simulation model of air bearing eccentric cross gap

\begin{tabular}{|c|c|c|}
\hline Parameters & Symbol & Value \\
\hline Bearing outside diameter, mm & $D_{1}$ & 80 \\
\hline $\begin{array}{c}\text { Distribution diameter of throttle } \\
\text { hole, mm }\end{array}$ & $D$ & 50 \\
\hline Diameter of throttle hole, $\mathrm{mm}$ & $D$ & 0.15 \\
\hline Depth of throttle hole, $\mathrm{mm}$ & $h_{1}$ & 0.25 \\
\hline Number of the throttle hole & $n$ & 4 \\
\hline Gap of air film, $\mu \mathrm{m}$ & $h$ & 20 \\
\hline Width of air film, mm & $a$ & 0.5 \\
\hline Depth of air film, mm & $b$ & 0.5 \\
\hline
\end{tabular}

Air bearing simulation model were composed by orifice, air film, and gap. The irregularly shaped model is divided into several regular geometry by using auxiliary surface and auxiliary body for meshing. The grid size along thickness direction is set to $1 \mu \mathrm{m}$. The grid size of gap is set to $0.05 \mathrm{~mm}$, its peripheral area is set to $0.4 \mathrm{~mm}$. The grid size of orifice is set to $0.02 \mathrm{~mm}$, its near area is set to $0.5 \mathrm{~mm}$, its far area is set to $1 \mathrm{~mm}$.

The boundary conditions of models of air bearing eccentric cross gap are mainly pressure inlet boundary, pressure outlet boundary, and solid wall boundary. The orifice inlet is set to pressure inlet boundary. The air film and its peripheral area is set to pressure outlet boundary. Other surfaces are set to soild wall boundary.

The geometrical models are built by using 3D modeling software SolidWorks and the grid partition and set of boundary conditions are done by mesh generation software Gambit. The models are shown in Fig. 4. Base on $\kappa-\varepsilon$ turbulence model, the performances of air bearing cross gap are analyzed by fluid dynamics software Fluent.

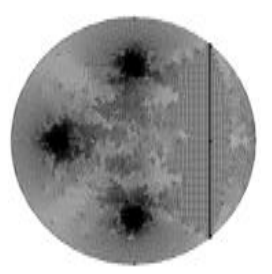

a

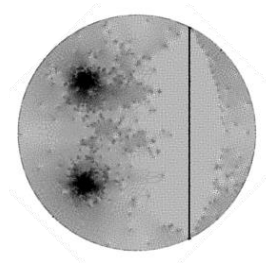

b
Fig. 4 Meshing of air bearing model: a - with two holes; b - with one hole 
The parameters of air bearing eccentric cross gap such as bearing capacity, air consumption, and overturning moment were calculated separately. Fig. 5 shows that the pressure distribution of air bearing eccentric cross gap is asymmetrical. The generated eccentric load and overturning moment would affect the normal operation of the bearing.

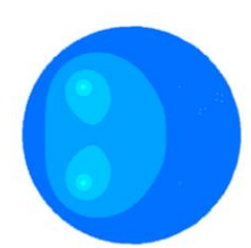

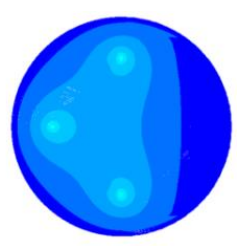

b

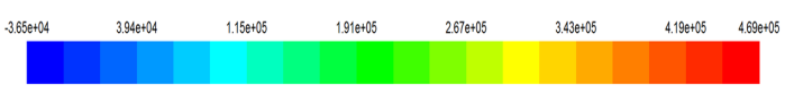

Fig. 5 Air bearing eccentric cross gap pressure distribution: a - with two holes; $b$ - with one hole

The bearing capacity, air consumption, and overturning moment of the air bearing of the two cases are shown in Table 2 . The bearing capacity of air bearing eccentric cross gap with two holes is larger than one hole. The overturning moment of the air bearing eccentric cross gap with two holes is larger than one hole. The overturning moments of the air bearing with non-cross gap and center cross gap are small, and do not affect the normal operation of the air bearing, but the overturning moment of the air bearing with eccentric cross gap is large, and would affect the normal operation of the air bearing.

Table 2

Bearing properties

\begin{tabular}{|c|c|c|c|}
\hline $\begin{array}{c}\text { Types of } \\
\text { cross gap }\end{array}$ & $\begin{array}{c}\text { Bearing } \\
\text { capacity, N }\end{array}$ & $\begin{array}{c}\text { Air cosumption, } \\
\mathrm{kg} \mathrm{s}^{-1}\end{array}$ & $\begin{array}{c}\text { Overturning } \\
\text { moment, N m }\end{array}$ \\
\hline $\begin{array}{c}\text { With two } \\
\text { holes }\end{array}$ & 106.6 & $5.7 \times 10^{-5}$ & 0.892 \\
\hline $\begin{array}{c}\text { With one } \\
\text { hole }\end{array}$ & 132.5 & $5.3 \times 10^{-5}$ & 0.809 \\
\hline
\end{tabular}

The simulation results show that bearing capacity and overturning moment of the air bearing are greatly changed under the eccentric cross gap.

\subsection{Research on performance of air bearing eccentric cross gap}

\subsubsection{Effect of air supply pressure on bearing capacity of} air bearing eccentric cross gap

The FE models of air bearing eccentric cross gap with two holes and one hole were built under $10 \mu \mathrm{m}$ to $25 \mu \mathrm{m}$ of air film thickness, the supply pressures are set to $0.4 \mathrm{MPa}, 0.5 \mathrm{MPa}$, and $0.6 \mathrm{MPa}$, the other setting of boundary and initial conditions are the same as the chapter 3.2 .

Fig. 6 shows that the variation of pressure distribution for different air supply pressures, when air film thickness is $20 \mu \mathrm{m}$, the high-pressure area and bearing capacity of air film are increased with the increase of air supply pressure.

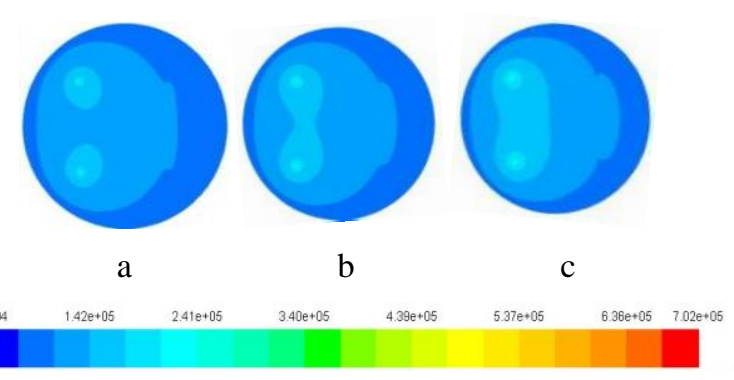

Fig. 6 Pressure distribution of air bearing eccentric cross gap with two holes: a-0.4 MPa; b-0.5 MPa; c - $0.6 \mathrm{MPa}$

3.3.2. Effect of gap width on bearing capacity and overturning moment of air bearing eccentric cross gap

The gap depth is set to $0.5 \mathrm{~mm}$ and the air supply pressure is set to $0.4 \mathrm{MPa}$. The chosen gap width are $0.5,1$, 1.5 , and $2 \mathrm{~mm}$. The bearing capacity and overturning moment of air bearing eccentric cross gap are shown in Fig. 7, a.

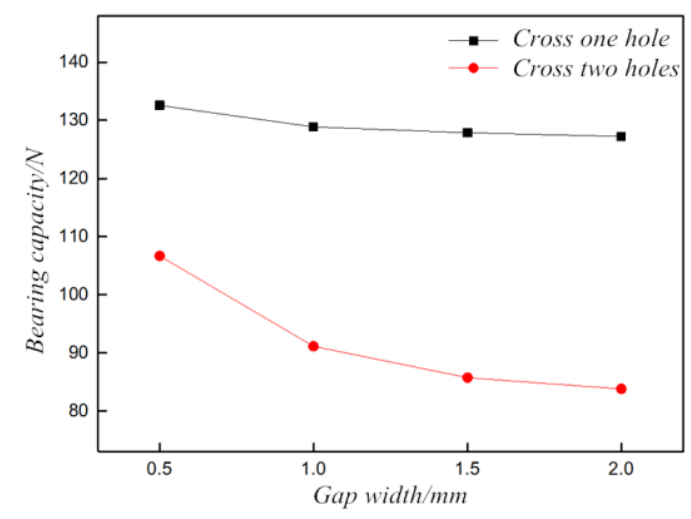

a

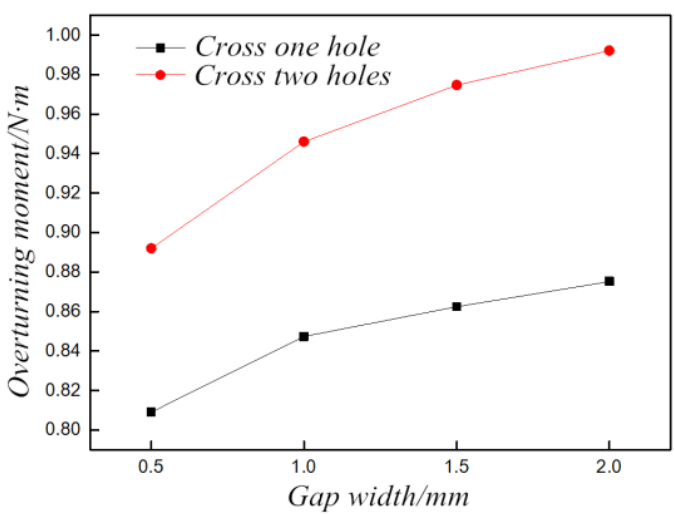

$\mathrm{b}$

Fig. 7 Effect of gap width on bearing capacity and overturning moment: a - varying curve of bearing capacity; $b$ - varying curve of overturning moment

Fig. 7, a shows that bearing capacity is decreased gradually with the increase of the gap width, but the decrease slows down. When the gap width is $0.5 \mathrm{~mm}$, the bearing capacity of the air bearing eccentric cross gap with two holes is about 1.27 times of that gap width is $2 \mathrm{~mm}$. When the gap width is less than $1 \mathrm{~mm}$, the bearing capacity decreases quickly. While the gap depth is more than $1 \mathrm{~mm}$, the decrease of the bearing capacity slows down. In addition, the bearing capacity of the air bearing eccentric 
cross gap with two holes is less than one hole, and the bearing capacity change rate of the air bearing eccentric cross gap with two holes is bigger than one hole. Result shows that the effect of increase of the gap width on air bearing eccentric cross gap with two holes is bigger. Therefore, when building the marble floor, the gap width should be less than $1 \mathrm{~mm}$ to ensure the air bearing capacity.

Fig. 7, b shows that overturning moment is increased gradually with the increase of the gap width, and the effect of gap width on two holes and one hole have the same influence tendency. When the gap width increases from $0.5 \mathrm{~mm}$ to $2 \mathrm{~mm}$, the increment of overturning moment of air bearing eccentric cross gap with two holes is $0.098 \mathrm{~N} \mathrm{~m}$, the increment of overturning moment of air bearing eccentric cross gap with one hole is $0.066 \mathrm{~N} \mathrm{~m}$, the increasing range of the overturning moment in two cases are basically the same. With the increase of the gap width, the effect of gap on air film area is increased and the air film bearing capacity of the area around the gap is decreased, that is the reason why the overturning moment of air bearing eccentric cross gap is increased.

\subsubsection{Effect of gap depth on bearing capacity and over-} turning moment of air bearing eccentric cross gap

The gap width is set to $0.5 \mathrm{~mm}$ and the air supply pressure is set to $0.4 \mathrm{MPa}$. The chosen gap depths are from $0.1 \mathrm{~mm}$ to $0.9 \mathrm{~mm}$. The bearing capacity and overturning moment of air bearing eccentric cross gaps are shown in Fig. 8, a.

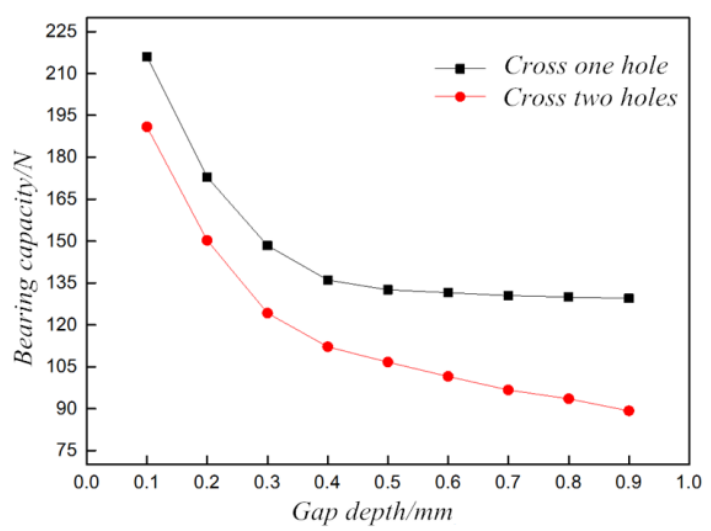

a

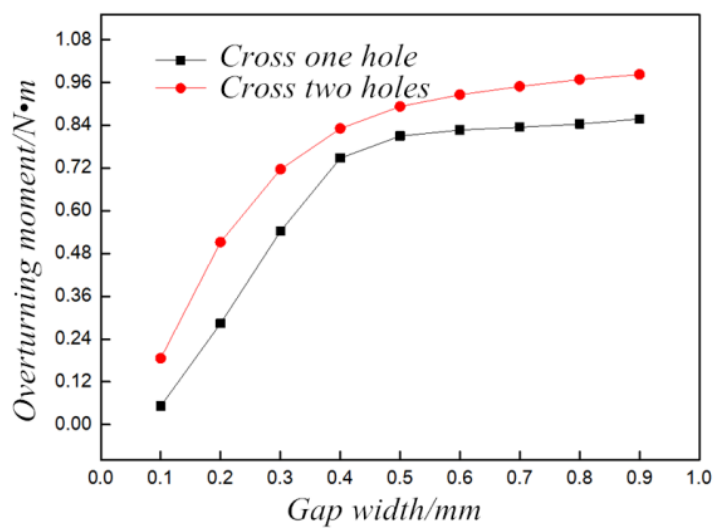

b

Fig. 8 Effect of the gap depth on bearing capacity and overturning moment: a - varying curve of bearing capacity; b - varying curve of overturning moment
Fig. 8, b shows that bearing capacity is decreased gradually with the increase of the gap depth, but the decrease slows down. When the gap depth is $0.1 \mathrm{~mm}$, the bearing capacity of the air bearing eccentric cross gap with two holes is about 1.67 times of that gap depth is $0.9 \mathrm{~mm}$. When the depth of the gap is less than $0.4 \mathrm{~mm}$, the bearing capacity decreases quickly. When the gap depth is more than $0.4 \mathrm{~mm}$, the decrease of the bearing capacity slows down. Therefore, when building the marble floor, the gap depth should be less than $0.4 \mathrm{~mm}$ to ensure the air bearing capacity.

Fig. 8, b shows that overturning moment is increased gradually with the increase of the gap depth. When the gap depth increases from $0.1 \mathrm{~mm}$ to $0.4 \mathrm{~mm}$, the increment of overturning moment of air bearing eccentric cross gap with two holes is $0.65 \mathrm{~N} \mathrm{~m}$. When the gap depth increases from $0.4 \mathrm{~mm}$ to $0.9 \mathrm{~mm}$, the increment of overturning moment of air bearing eccentric cross gap with two holes is $0.15 \mathrm{~N} \mathrm{~m}$. Result suggests that the overturning moment increases rapidly when the gap depth less than $0.4 \mathrm{~mm}$. When the gap width is small, the air film bearing capacity is decreased rapidly with the increase of the gap depth. When the gap depth increases to some extent, the air film bearing capacity would vary slightly with the variation of the gap depth.

3.3.4. Effect of gap height difference on bearing capacity and overturning moment of air bearing eccentric cross gap

As can be seen in Fig. 9, the bottom area of the air bearing could be divide into side A and side B. The side A include the orifice of non-cross gap, thus, side $\mathrm{A}$ is the main bearing zone. The side B does not include orifice, thus, the bearing capacity of side B is low and the bearing capacity of side B would vary slightly with the variation of the air film height. Hence, during the course of the analysis, it is more meaningful to realize different gap height difference by increasing the gas film thickness of side A.The gap width is set to $0.5 \mathrm{~mm}$ and the air supply pressure is set to $0.4 \mathrm{MPa}$. The chosen gap height differences are 5, 10, 15 , and $20 \mu \mathrm{m}$. The bearing capacity and overturning moment of air bearing eccentric cross gaps are shown in Fig. 10

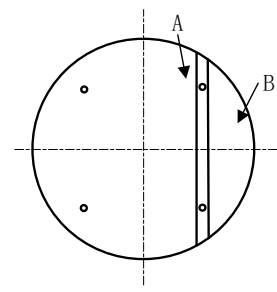

a

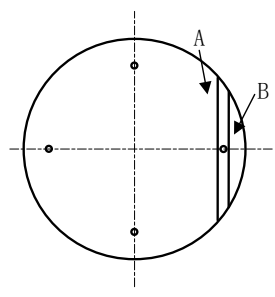

b
Fig. 9 Schematic drawing of gap height difference: a - with two holes; $b$ - with one hole

Fig. 10, a shows that the height difference of the gap would obviously decrease the bearing capacity. When the height difference of the gap is $20 \mu \mathrm{m}$, the bearing capacity is $39.8 \%$ of the bearing capacity when no height difference exist. Fig. 10, b shows that the overturning moment of the air bearing is decreased with the increase of the height difference. 


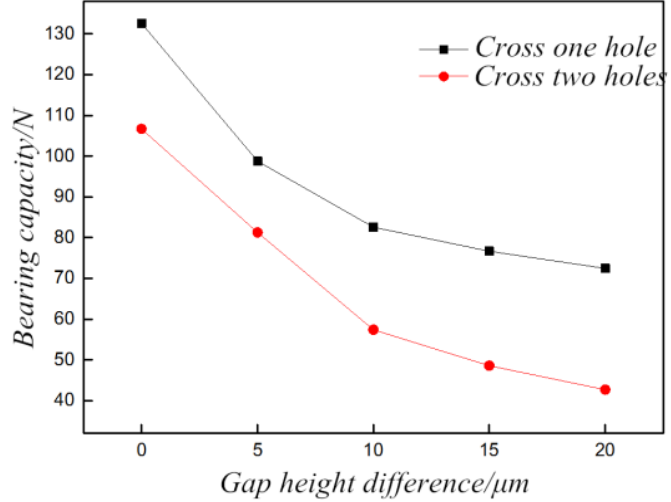

a

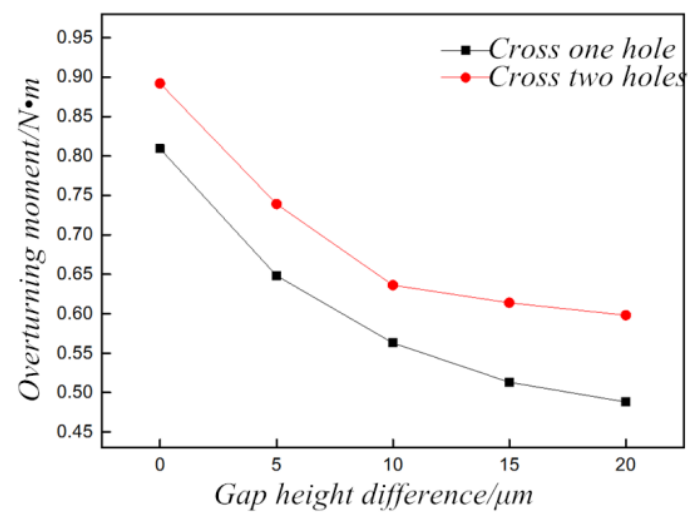

$\mathrm{b}$

Fig. 10 Effect of gap height difference on bearing capacity and overturning moment: a-varying curve of bearing capacity; $b$ - varying curve of overturning moment

\section{Experimental study}

\subsection{Experimental principle and equipment}

The neended equipment: air compressor, cold dry machine, a pressure regulating device, supporting block, vibration isolation table, air bearing (Fig. 11), and a dial indicator.

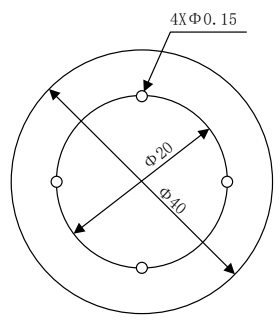

a

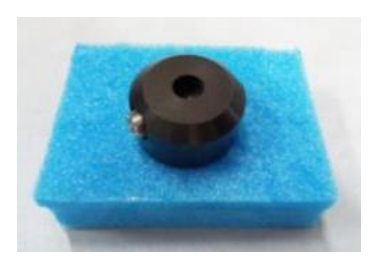

b
Fig. 11 Air bearing: a - dimensional drawing; $b$ - product picture

\subsection{Experimental procedure and results}

As shown in Fig. 12, the supporting glasses were placed on the vibration isolation table, The gap of the two supporting plates are then adjusted to the required size. Then, the bearing is marked and the position of the bearing is adjusted. The position of the bearing is recorded by use of the dial indicator. The air supply pressure is adjusted to set the value by the pressure valve. The position of air bearing when the air bearing is stable is then recorded. Constantly adjusting the load of the weight would make the air film thickness reach the desired value. The total mass of the load at this time is then recorded.

To analyze the influence of air film thickness on bearing capacity, the gap between the glass support plate is ensured at $0.5 \mathrm{~mm}$. Air film thickness is adjusted to 10, 15, 20 , and $25 \mu \mathrm{m}$. Measurement is conducted three times to select the average value. To analyze the influence of gap depth on air bearing cross gap capacity, the air pressure is ensured at 0.4 MPa. Air film thickness should remain at $20 \mu \mathrm{m}$ by adjusting the weight of load. Gap between two glass blocks is adjusted to $0.5,1,1.5$, and $2 \mathrm{~mm}$. Measurement is conducted three times to select the average value.

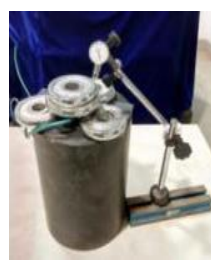

a

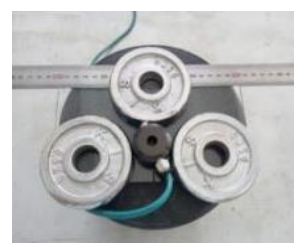

$\mathrm{b}$

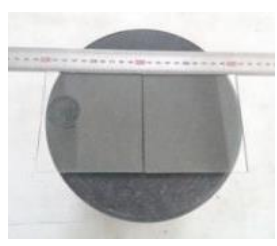

C
Fig. 12 Experimental process: a - experiment equipment; $\mathrm{b}$ - pressing of supporting block; $\mathrm{c}$ - adjustment of gap width

Table 3

Bearing capacity of air bearing eccentric cross gap with one hole

\begin{tabular}{|c|c|c|}
\hline $\begin{array}{c}\text { Gap width, } \\
\mathrm{mm}\end{array}$ & $\begin{array}{c}\text { Air film thickness, } \\
\mu \mathrm{m}\end{array}$ & $\begin{array}{c}\text { Bearing capacity, } \\
\mathrm{N}\end{array}$ \\
\hline 0.5 & 10 & 70.5 \\
\hline 0.5 & 15 & 44.7 \\
\hline 0.5 & 20 & 29.5 \\
\hline 0.5 & 25 & 18.1 \\
\hline 1 & 20 & 26.1 \\
\hline 1.5 & 20 & 24.6 \\
\hline 2 & 20 & 24.3 \\
\hline
\end{tabular}

Table 4

Bearing capacity of air bearing eccentric cross gap with two holes

\begin{tabular}{|c|c|c|}
\hline $\begin{array}{c}\text { Gapwidth, } \\
\mathrm{mm}\end{array}$ & $\begin{array}{c}\text { Air film thickness, } \\
\mu \mathrm{m}\end{array}$ & $\begin{array}{c}\text { Bearingcapacity, } \\
\mathrm{N}\end{array}$ \\
\hline 0.5 & 10 & 58.8 \\
\hline 0.5 & 15 & 31.9 \\
\hline 0.5 & 20 & 22.7 \\
\hline 0.5 & 25 & 13.9 \\
\hline 1 & 20 & 20.4 \\
\hline 1.5 & 20 & 19.1 \\
\hline 2 & 20 & 18.5 \\
\hline
\end{tabular}

In analyzing the influence of air film thickness on bearing capacity, ensure that the air pressure is $0.4 \mathrm{MPa}$. Air film thickness should be adjusted to the required value by changing the load weight, and the air bearing capacity is shown in Tables 3 and 4. The tables show that the air bearing capacity is relatively large when air film thickness is low. Hence, the air bearing capacity is decreased with the increase of the air film thickness. To study the influ- 
ence of the gap width on the bearing capacity of the air bearing, ensure that air pressure remians at $0.4 \mathrm{MPa}$ and the air film thickness is $20 \mu \mathrm{m}$. The gap widths were changed to $0.5,1,1.5$, and $2 \mathrm{~mm}$, and the air bearing capacity results are shown in Tables 3 and 4 . The tables show that bearing capacity decrease with the increase of the gap width, but the decrease of the bearing capacity slows down.

\subsection{Comparative analysis of simulation and experiment}

The finite element model of air bearing used in the experiment is established and the numerical calculation is carried out by using the simulation method presented in Section 3. The bearing capacity varies with thickness and gap width of the air film, as shown in the following figures. Figure 13 shows that when air pressure is $0.4 \mathrm{MPa}$ and the gap width is $0.5 \mathrm{~mm}$, the air bearing eccentric cross gap capacity varies with air film thickness. Fig. 14 shows that when the air pressure is $0.4 \mathrm{MPa}$ and air film thickness is $20 \mu \mathrm{m}$, the air bearing eccentric cross gap capacity varies with gap width.

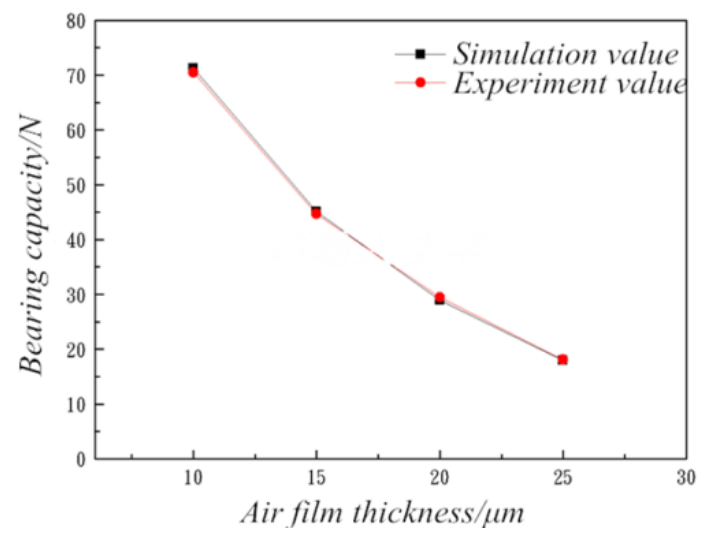

a

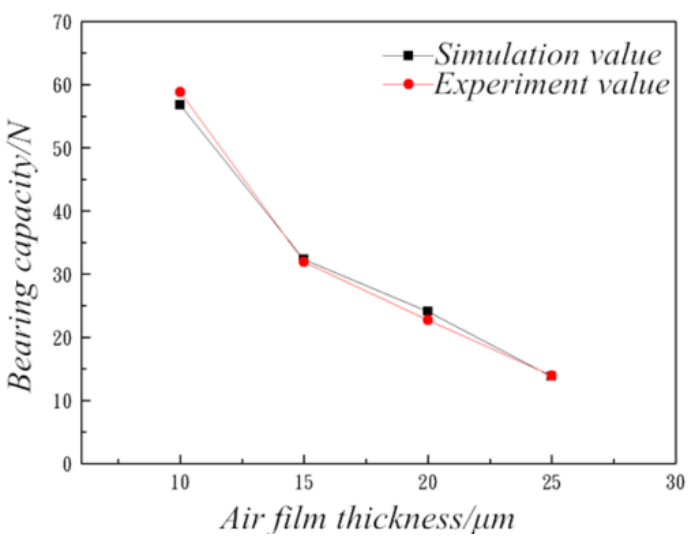

b

Fig. 13 Effect of air film thickness on bearing capacity: $\mathrm{a}$ - eccentric cross gap with one hole; $\mathrm{b}$ - eccentric cross gap with two holes

Fig. 13 and 14 shows that air bearing eccentric cross gap capacity decrease with the increase of the air film thickness and the gap width. The simulation results are in agreement with the experimental results. Under different air film thicknesses, the maximum error of the bearing capacity between the experimental value and the simulation value is $13 \%$, This error happens when film thick- ness is $10 \mu \mathrm{m}$. Given that the film thickness is small and close to measuring accuracy of micrometer, the measurement error increases, and the experiment error is relatively large. Fig. 14 shows that experimental values of the air bearing capacity are in good agreement with the simulation results, and the maximum error is $10 \%$. By the analysis, the FE simulation results are consistent with the experimental results, which prove the rationality and accuracy of the FE models for air bearing cross gap.

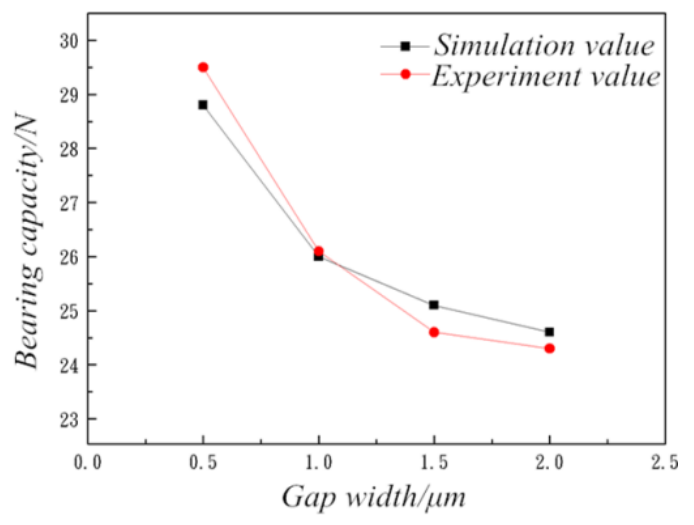

$\mathrm{a}$

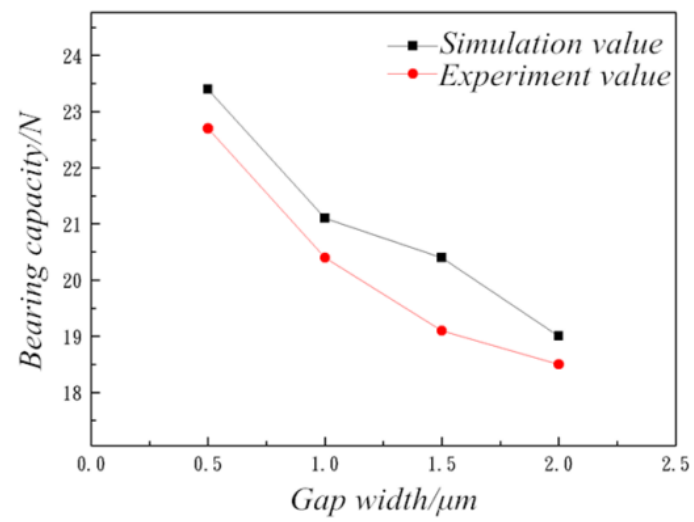

b

Fig. 14 Effect of gap width on bearing capacity: a - eccentric cross gap with one hole; b - eccentric cross gap with two holes

The comparison between the experimental and the simulation results shows some errors. The main reasons are as follows. First, the air film thickness of air bearing is very small, Hence, the measuring accuracy of the experimental apparatus is limited, and thus, the measuring error is relatively large when the air film thickness is small. Second, the condition of pressure inlet and outlet ignores the influence of air pressure fluctuation and the environment. Third, due to use of glass as support block and the gap is made of artificial adjustment, the condition will produce some deviations inevitably. Finally, the making process of air bearing and supporting will produce the manufacturing error.

\section{Conclusion}

In this paper, the sample table of the neutron stress spectrometer was designed and the function of the support system of the sample table was analyzed. Then, the FE models of air bearing were established and the corresponding research work was carried out. The results are as 
follows:

First, the bearing capacity and overturning moment of the support system is affected greatly by air bearing eccentric cross gap, and would vary with the variation of the air supply pressure, gap depth, gap width, and gap height difference.

Second, the bearing capacity and overturning moment of air bearing eccentric cross gap are increased with the increase of air supply pressure. The air bearing eccentric cross gap capacity decreases with the increase of the gap width and gap depth. The air bearing eccentric cross gap overturning moment increases with the increase of the gap width and gap depth. When gap height difference exists in the marble floor, the air bearing eccentric cross gap capacity is decreased rapidly.

Third, the effect of gap width and gap depth on the bearing capacity and overturning moment of air bearing eccentric cross gap is the same. When the gap width is below $1 \mathrm{~mm}$ and the depth is below $0.4 \mathrm{~mm}$, the bearing capacity and overturning moment change quickly with the increase of the gap width and depth. Thus, when building the marble floor of the neutron stress spectrometer, the gap width should be within $1 \mathrm{~mm}$ and gap depth within $0.4 \mathrm{~mm}$ to ensure stability of the support system. A gap height in the marble floor exist results in the air bearing eccentric cross gap capacity decreasing rapidly. Thus, when building the marble floor, the height difference of the gap should be strictly controlled to ensure the good performance of the support system.

Finally, experimental results show that the model is correct and provides a reference for further research on this kind of instrument.

\section{Acknowledgements}

This study is supported by the National Natural Science Foundation of China (Grant Nos. 51405520 and 51327902), and the Autonomous Research Topic Fund of State Key Laboratory of High Performance Complex Manufacturing (Grant No. 2014bcxjj06).

\section{References}

1. Chen, M.F.; Lin, Y.T. 2002. Static behavior and dynamic stability analysis of grooved rectangular aerostatic thrust bearings by modified resistance network method, Tribology International 35(5): 329-338. http://dx.doi.org/10.1016/S0301-679X(02)00012-9.

2. Renn, J.; Hsiao, C. 2004. Experimental and CFD study on the mass flow-rate characteristic of air through orifice-type restrictor in aerostatic bearings, Tribology International 37(4): 309-315. http://dx.doi.org/10.1016/j.triboint.2003.10.003.

3. Luong, T.S.; Potze, W.; Post, J.B.; et al. 2004. Numerical and experimental analysis of aerostatic thrust bearings with porous restrictors, Tribology International 37(10): 825-832.

http://dx.doi.org/10.1016/j.triboint.2004.05.004.

4. Belforte, G.; Raparelli, T.; Viktorov, V.; et al. 2007. Discharge coefficients of orifice-type restrictor for aerostatic bearings, Tribology International 40(3): 512-521.

http://dx.doi.org/10.1016/j.triboint.2006.05.003.

5. Li, Y.; Ding, H. 2007. Influences of the geometrical parameters of aerostatic thrust bearing with pocketed orifice -type restrictor on its performance, Tribology International 40(7): 1120-1126.

http://dx.doi.org/10.1016/j.triboint.2006.11.001.

6. Stout, K.J.; Barrans, S.M. 2000. The design of aerostatic bearings for application to nanometre resolution manufacturing machine systems, Tribology International 33(12): 803-809.

http://dx.doi.org/10.1016/S0301-679X(00)00118-3.

7. Belforte, G.; Colombo, F.; Raparelli, T.; et al. 2010. Performance of externally pressurized grooved thrust bearings, Tribology Letters 37(3): 553-562.

http://dx.doi.org/10.1007/s11249-009-9550-3.

8. Belforte, G.; Colombo, F.; Raparelli, T.; et al. 2011. Comparison between grooved and plane aerostatic thrust bearings: static performance, Meccanica 46(3): 547-555.

http://dx.doi.org/10.1007/s11012-010-9307-y.

9. Eleshaky, M.E. 2009. CFD investigation of pressure depressions in aerostatic circular thrust bearings, Tribology International 42(7): 1108-1117. http://dx.doi.org/10.1016/j.triboint.2009.03.011.

10. Miyatake, M.; Yoshimoto, S. 2010. Numerical investigation of static and dynamic characteristics of aerostatic thrust bearings with small feed holes, Tribology International 43(8): 1353-1359.

http://dx.doi.org/10.1016/j.triboint.2010.01.002.

11. Hou, Y.; Zhao, X.; Chen, S.; et al. 2008. Numerical analysis of exterally pressurized gas thrust bearing with supply hole, Lubrication Engineering 33(9): 1-3 (in Chinese).

http://dx.doi.org/10.3969/j.issn.0254-0150.2008.09.001

12. Huang, H.; Liu, P.; Dong, Z. 2010. The Performances simulation of aerostatic thrust bearing, Computer Simulation 28(3): 340-343 (in Chinese).

http://dx.doi.org/10.3969/j.issn.1006-9348.2010.03.083

13. Long, W. 2010. Study on loading characteristics of orifice compensated aerostatic thrust bearing, Dissertation for the Doctoral Degree, Harbin: Harbin Institute of Technology (in Chinese).

14. Long, W.; Li, J.; Bao, G. 2006. Application of FLUENT in the research of air bearing field, Machine Tool \& Hydraulics 36(6): 151-153 (in Chinese).

http://dx.doi.org/10.3969/j.issn.1001-3881.2006.06.055

15. Zhang, J. 2006. Research on higher stiffness aerostatic bearing, Dissertation for the Doctoral Degree, Xi'an: Northwestern Polytechnical University (in Chinese). http://dx.doi.org/10.7666/d.y1189926.

16. Li, Y.; Lin, Y.; Zhu, H. 2013. Performances analysis of aerostatic bearing restricted by fan-shaped surface restrictor, Computer Simulation 30(4): 243-247 (in Chinese).

http://dx.doi.org/10.3969/j.issn.1006-9348.2013.04.055

17. Liu, S. 2012. Numerical simulation and experimental investigation of the static characteristics of a vacuum preloaded aerostatic bearing, Dissertation for the Master's Degree, Wuhan: Huazhong University of Science and Technology (in Chinese).

18. Liu, D.; Liu, Y.; Chen, S. 1990. Lubrication of aerostatic bearing, Harbin: Harbin Institute of Technology Press (in Chinese).

19. He, X. 2007. Dynamics of the ultra-precision positioning stage with gas-lubricated bearings, Dissertation for the Doctoral Degree, Wuhan: Huazhong University of 
Science and Technology (in Chinese). http://dx.doi.org/10.7666/d.d093480.

20. Xiang, Y. 2012 Study of static and dynamic characteristics of planar aerostatic bearings, Dissertation for the Doctoral Degree, Wuhan: Huazhong University of Science and Technology (in Chinese).

Li, Y., Wu, Y.

\section{RESEARCH ON AIR BEARING ECCENTRIC CROSS GAP OF NEUTRON STRESS SPECTROMETER SAMPLE TABLE SUPPORT SYSTEM}

\section{S u m mary}

A support system is the main load-bearing component of sample table for neutron stress spectrometer and air bearing is an important element of support system. The neutron stress spectrometer sample table was introduced, and the scheme for air bearing combination was selected. To study the performance of air bearing eccentric cross gap, finite element models (FEMs) were established based on air motion and Reynolds equations, effects of types of cross gap, air supply pressure and gap parameters on the overturning moment and bearing capacity of air bearing eccentric cross gap were analyzed. Results indicate that the overturning moment of air bearing with eccentric cross gap is large, and the overturning moment of air bearing cross two holes is larger than cross one hole. The width, depth, and height differences of the marble floor gap played important roles in the performance of the air bearing. When gap width is lesser than $1 \mathrm{~mm}$ and gap depth is lower than $0.4 \mathrm{~mm}$, bearing capacity and overturning moment would vary rapidly with the variation of the width and depth. A gap height difference results in the bearing capacity dropping rapidly. The FEM results agree well with experimental results. Further, fingdings of the study could guide the design of the support system and marble floor.

Keywords: neutron stress spectrometer, sample table, support system, air bearing, eccentric cross gap, experiment.

Received January 26, 2016

Accepted April 14, 2017 